\title{
Patients' Responses to the Sudden Interruption of Chemotherapy During the Outbreak of the Novel Coronavirus: A Cross-Sectional Study
}

This article was published in the following Dove Press journal: Cancer Management and Research

\author{
Hao Zhang ${ }^{1, *}$ \\ Jianhao Yin ${ }^{1, *}$ \\ Xin Wang ${ }^{2}$ \\ Dawei Yuan' \\ Kun Zhu' \\ Kang Li (D) $)^{\prime}$ \\ Gang $X u^{\prime}$ \\ Chengxue Dang' \\ Rui Jia' \\ Yong Zhang'
}

'Department of Surgical Oncology, The First Affiliated Hospital of Xi'an Jiaotong University, Xi'an, Shaanxi 71006I,

People's Republic of China; ${ }^{2}$ Department of General Surgery, The Second Hospital of Weinan, Weinan, Shaanxi 714000,

People's Republic of China

*These authors contributed equally to this work
Correspondence: Yong Zhang

Department of Surgical Oncology, The

First Affiliated Hospital of Xi'an Jiaotong

University, Xi'an, Shaanxi 71006I,

People's Republic of China

Tel +86 I3709II 0938

Email yongzhang76I@mail.xjtu.edu.cn
Purpose: This cross-sectional study aimed to describe the responses of cancer patients' indifferent chemotherapy cycles to the unstructured treatment interruption during the COVID-19 pandemic in China.

Patients and Methods: Data from 156 adult patients with common solid tumors undergoing chemotherapy or ready to begin chemotherapy after surgery before the COVID-19 outbreak were analyzed in the study. Patients' responses to the chemotherapy interruption and their anxiety were assessed.

Results: Overall, 141 (90\%) patients completed the study, and 115 (81.6\%) accepted a switch from their previous intravenous chemotherapy to oral chemotherapy. Of these, $29(65.9 \%)$ patients with lung cancer, $25(86.2 \%)$ with gastric cancer, $33(89.2 \%)$ with colorectal cancer and $28(90.3 \%)$ with breast cancer switched from intravenous to oral treatment, heeding their doctor's advice. Of the participants, $85(60.3 \%)$ patients reported that they had taken at least one kind of complementary and alternative medicine (CAM). The hospital anxiety and depression scale (HADS) scores increased in patients with advanced refractory cancer compared with the scores of adjuvant chemotherapy patients $(P<0.05)$. The prevalence of anxiety was high in cancer patients aged 60 years or older. Furthermore, anxiety was associated with advanced incurable cancer $(P<0.05)$, and this finding remained after adjusting for chronic pain. In addition, there were significantly increased scores of anxiety in patients with lung cancer $(P<00.05)$.

Conclusion: Our study shows that most cancer patients remained relatively stable and had switched from intravenous to oral treatment at home. Among them, an increasing number of patients began to seek CAM as a complementary therapeutic approach. Patients with advanced refractory cancer were more likely to experience anxiety, and lung cancer patients should receive special attention.

Keywords: chemotherapy interruption, complementary and alternative medicine, mental health, COVID-19

\section{Introduction}

The type of pneumonia caused by the 2019 novel coronavirus (COVID-19) has had a significant impact on global health since early December 2019 and has been labeled a pandemic by the World Health Organization (WHO). ${ }^{1}$ The outbreak has become a major epidemic threat in China and is affecting 200 countries and territories around the world. This pandemic has caused nearly 16,000,000 confirmed COVID-19 cases and claimed over 650,000 lives worldwide as of 27 July $2020 .^{2}$ 
Thirty-one provinces and municipalities in mainland China have initiated the first-level urgent response to this major public health emergency. Nearly 43,000 medical personnel have been parachuted to Hubei Province, the front line of the epidemic, to prevent and fight the disease. The Chinese government has prioritized and allocated health and medical resources to respond to the spread of COVID-19; given the current trends and situation, in order to reduce the potential of cross-contamination and save medical resources, many hospitals have cancelled outpatient appointments and reduced avoidable hospitalizations, except for emergency and fever clinics. The pandemic will consume significant health care resources and cause staffing shortages. This will significantly impair the diagnosis and treatment of patients with other diseases. The COVID-19 pandemic has prompted many doctors to develop different treatment strategies for cancer and other chronic conditions. ${ }^{3}$ Cancer patients who were undergoing chemotherapy or were ready to initiate chemotherapy after surgery were forced to suspend their treatment because of the epidemic. This is a topical issue as there has been much reporting that cancer patients are suffering while diseases go untreated under circumstances never faced before. Oncologists should bear in mind that patients with cancer have more anxiety than expected under the unprecedented circumstances, such as the COVID-19 pandemic. ${ }^{4}$ This study aimed to describe the appropriate response measures taken by patients and the changes in their psychological and spiritual well-being during these extraordinary circumstances.

\section{Patients and Methods}

\section{Patients}

The inclusion criteria in this study were as follows: cancer patients (with the most common solid tumors in the region, including lung, gastric, colorectal and breast cancer) older than 18 years, complete consciousness, capable and willing to answer questions, and received care in the Cancer Center at The First Affiliated Hospital of Xi'an Jiaotong University and were discharged from the hospital just before the COVID-19 outbreak. Ethics approval was granted by The Review Boards of Shaanxi Province Clinical Cancer Research Center affiliated to The First Affiliated Hospital of Xi' an Jiaotong University (No.SXZLLC-2020-09).

\section{Interview Methods}

All telephone interviews were conducted between 9-11 am and $3-5 \mathrm{pm}$ by one trained medical researcher. An average of 10 minutes was dedicated to each interview for every patient. At the beginning of each call, the researcher introduced himself/herself, explained the objectives of the project, and invited patients to participate in the study. After acceptance, oral consent to participate was obtained to continue the study. The telephone interviews were conducted from February 21st to 29th, 2020.

Self-reporting in the form of telephone interviews comprised five main domains: (1) demographics: age, sex, educational level, marital status, average household incomes, types of health insurance and occupation; (2) lifestyle: weight, height, physical activity, smoking, alcohol intake, and eating habits; (3) medical history; (4) outcome assessment of chronic pain; and (5) patients' responses to the forced break of chemotherapy. Six descriptive questions were also included in the interview: (1) What is the status of your chemotherapy, and did you discuss with your doctors and accept the doctors' advice? (2) What do you think your chemotherapy purposes is? Cure or just palliative care? Response options were "Very clear," "Know a little bit," and "Not at all." (3) Are there some other more proactive approaches that you intend to use, such as Chinese traditional medicine? (4) Do you consider home-based chemotherapy to be feasible or safe? (5) Would you worry about the maintenance of Peripherally Inserted Central Venous Catheters (PICC) or Versus Subcutaneously Implanted Port-Chamber Catheters? (6) Were there any further impeding subjective factors that influenced the temporary suspension of chemotherapy, such as fear of infection with the novel coronavirus?

Chronic pain was defined in accordance with the conventional definition by the International Association for the Study of Pain, and intensity was evaluated using a numeric pain rating scale from 0 (no pain) to 10 (worst pain imaginable). Scores of 1-3 were categorized as light pain, 4-7 as moderate pain, and $8-10$ as severe pain. Anxiety symptoms were assessed using the hospital anxiety and depression scale (HADS), which is a wellvalidated measure of both anxiety and depression and acts as one of the most frequently used self-reported tools in cancer practice. ${ }^{5}$ The HADS contains seven anxiety and seven depression items rated on a scale from 0 to 3 and were read to the patients for selection by the researcher.

The questionnaire was based on a review of the relevant literature and expert opinions. ${ }^{6-8}$ The psychometrics characteristics of the questions were reviewed by three 
medical ethics experts using a qualitative method. The content validity of the questions and the comprehensiveness of the questionnaire for the study objectives were confirmed after a few revisions. To enhance the clarity of the questions, a pilot study was conducted on 10 individuals.

\section{Data Analysis}

Data were analyzed using $\mathrm{R}$ program. Quantitative variables were expressed as the means $\pm \mathrm{SD}$ or as the medians and interquartile range, depending on their distribution. For categorical variables, the percentages of patients in each category were calculated. Logistic regression was used to identify risk factors in univariate and multivariate analysis, and those with $P$ value $<0.05$ in univariable analyses were included in the multivariate model. Odds ratios (ORs) and 95\% confidence intervals (CIs) were calculated for each independent variable. Tests were 2-tailed, and $P<0.05$ was considered statistically significant.

\section{Results}

\section{The Characteristics of Patients}

We (Jianhao Yin and Xin Wang) telephone-interviewed 156 patients who were undergoing chemotherapy or ready to initiate the next cycle of chemotherapy before the outbreak of COVID-19 in The First Affiliated Hospital of Xi'an Jiaotong University from February 21st to 29th, 2020. In total, 141 patients completed the survey, including 44 lung cancer patients, 29 gastric cancer patients, 37 colorectal cancer patients and 31 breast cancer patients. Overall, 136 (96.5\%) patients claimed that the chemotherapy was interrupted or delayed due to the outbreak of COVID-19, and 139 of 141 patients telephoned or made online consultations to their physician to seek further alternative options.

After full communication with their doctors, 115 $(81.6 \%)$ patients accepted the switch from their previous intravenous chemotherapy to oral chemotherapy for further therapy during the COVID-19 outbreak period, including $29(65.9 \%)$ lung cancer patients, 25 (86.2\%) gastric cancer patients, $33(89.2 \%)$ colorectal cancer patients and $28(90.3 \%)$ breast cancer patients. Most lung cancer patients who did not take the appropriate oral chemotherapy switch did so because of lack of appropriate drug administration indications. The primary consideration of the remaining patient who did not accept the switch was regarding how to cope with the side effects of oral chemotherapy at home. In addition to oral chemotherapy drugs, 72 patients, including 19 lung cancer patients, 23 gastric cancer patients, 19 colorectal cancer patients and 24 breast cancer patients, reported they had taken at least one kind of complementary and alternative medicine (CAM, of which 3 patients chose acupuncture, 67 patients chose Chinese herbal medicine and 2 patients chosen Tai chi chuan) as a complementary strategy for the purpose of improving physical and general well-being, fighting cancer and relieving side effects from chemotherapy. In addition, another 13 patients who did not switch to oral chemotherapy also reported CAM use. Among all the 85 CAM users (60.3\%), only 22 patients $(25.9 \%)$ had discussed CAM with their physician or nurse. The details are shown in Table 1.

\section{Anxiety Among Patients}

For HADS, when the critical value of anxiety is 11 points, the reliability and validity are both satisfactory. Therefore, patients with a score greater than 10 (11 or more points) were labeled as "anxious" and 10 points were taken as the critical value of anxiety in the study. The anxiety score regarding the delay of chemotherapy is shown in Table 1. There were statistically significant differences in sex, disease, tumor stage, education background, switch to oral chemotherapy or not, choice of CAM or not, and knowing the purpose of their treatment or not $(P<0.05)$. After multivariate analysis, the anxiety scores of different diseases, advanced stage, switching to oral chemotherapy or not, choosing alternative medical treatment or not, and knowing the purpose of their treatment or not were significantly different (Table 2). According to the score, patients with lung cancer, advanced stage (stage IV), without oral chemotherapy and alternative treatment achieved higher scores.

\section{Anxiety Intervention}

Patients with lung cancer who suffered more advanced tumors and failed to switch to oral drugs due to genotype received higher scores. Finally, for the 10 patients who failed to switch their treatment and had a score more than 11 , most showed significantly decreased scores after psychological counseling, support, guidance and teaching via telephone (Figure 1).

\section{Discussion}

The coronavirus has caused significant disruptions worldwide. The rapidly evolving COVID-19 pandemic is 
Table I The Characteristics of Patients and Results of Univariate Logistic Regression $(n=|4|)$

\begin{tabular}{|c|c|c|c|c|}
\hline & & $\begin{array}{l}\text { Number of Patients } \\
\text { (\%) }\end{array}$ & Anxiety Score (Mean \pm SD) & $P$ value \\
\hline Gender & $\begin{array}{l}\text { Male } \\
\text { Female }\end{array}$ & $\begin{array}{l}61(43.3 \%) \\
80(56.7 \%)\end{array}$ & $\begin{array}{l}12.64 \pm 4.16 \\
10.21 \pm 5.33\end{array}$ & 0.004 \\
\hline Age & $\begin{array}{l}\leq 60 \\
>60\end{array}$ & $\begin{array}{l}85(60.3 \%) \\
56(39.7 \%)\end{array}$ & $\begin{array}{l}11.16 \pm 4.97 \\
11.41 \pm 5.06\end{array}$ & 0.776 \\
\hline Marital status & $\begin{array}{l}\text { Married } \\
\text { Widowed or divorced }\end{array}$ & $\begin{array}{l}77(54.6 \%) \\
64(45.4 \%)\end{array}$ & $\begin{array}{l}11.79 \pm 4.98 \\
10.62 \pm 4.97\end{array}$ & 0.167 \\
\hline Place of residence & $\begin{array}{l}\text { Rural } \\
\text { Urban }\end{array}$ & $\begin{array}{l}24(17.0 \%) \\
117(83.0 \%)\end{array}$ & $\begin{array}{l}12.83 \pm 4.97 \\
10.94 \pm 4.95\end{array}$ & 0.09 \\
\hline Tumor location & $\begin{array}{l}\text { Lung } \\
\text { Breast } \\
\text { Colorectal } \\
\text { Gastric }\end{array}$ & $\begin{array}{l}44(31.2 \%) \\
31(22.0 \%) \\
37(26.2 \%) \\
29(20.6 \%)\end{array}$ & $\begin{array}{l}14.14 \pm 3.96 \\
7.90 \pm 4.69 \\
10.51 \pm 5.06 \\
11.45 \pm 4.21\end{array}$ & $<0.001$ \\
\hline Advanced patients & $\begin{array}{l}\text { Yes } \\
\text { No }\end{array}$ & $\begin{array}{l}48(34.0 \%) \\
93(66.0 \%)\end{array}$ & $\begin{array}{l}\mid 5.35 \pm 2.18 \\
9.15 \pm 4.7 \mid\end{array}$ & $<0.001$ \\
\hline Education & $\begin{array}{l}\text { Bachelor or above } \\
\text { Others }\end{array}$ & $\begin{array}{l}30(21.3 \%) \\
111(78.7 \%)\end{array}$ & $\begin{array}{l}8.73 \pm 4.46 \\
11.95 \pm 4.92\end{array}$ & 0.002 \\
\hline Incomes* & $\begin{array}{l}\geq 20 \\
<20\end{array}$ & $\begin{array}{l}19(13.5 \%) \\
122(86.5 \%)\end{array}$ & $\begin{array}{l}\text { II. } .05 \pm 5.20 \\
\text { II. } 30 \pm 4.98\end{array}$ & 0.845 \\
\hline Health insurance & $\begin{array}{l}\text { Some } \\
\text { None }\end{array}$ & $\begin{array}{l}83(58.9 \%) \\
58(41.1 \%)\end{array}$ & $\begin{array}{l}10.59 \pm 5.24 \\
12.22 \pm 4.47\end{array}$ & 0.055 \\
\hline Switch to oral chemotherapy & $\begin{array}{l}\text { Yes } \\
\text { No }\end{array}$ & $\begin{array}{l}115(81.6 \%) \\
26(18.4 \%)\end{array}$ & $\begin{array}{l}10.57 \pm 4.94 \\
|4.3| \pm 4.07\end{array}$ & $<0.001$ \\
\hline CAM & $\begin{array}{l}\text { With } \\
\text { Without }\end{array}$ & $\begin{array}{l}85(60.3 \%) \\
56(39.7 \%)\end{array}$ & $\begin{array}{l}10.00 \pm 5.19 \\
|3.18 \pm 4.0|\end{array}$ & $<0.001$ \\
\hline Knowing the purpose of chemotherapy & $\begin{array}{l}\text { Nothing } \\
\text { Clear }\end{array}$ & $\begin{array}{l}96(68.1 \%) \\
45(31.9 \%)\end{array}$ & $\begin{array}{l}10.28 \pm 4.85 \\
13.36 \pm 4.67\end{array}$ & 0.001 \\
\hline Chronic pain & $\begin{array}{l}\text { With } \\
\text { Without }\end{array}$ & $\begin{array}{l}28(19.9 \%) \\
113(80.1 \%)\end{array}$ & $\begin{array}{l}12.36 \pm 4.36 \\
10.99 \pm 5.12\end{array}$ & 0.196 \\
\hline Vein access & $\begin{array}{l}\text { Without } \\
\text { PICC } \\
\text { Port }\end{array}$ & $\begin{array}{l}21 \text { (14.9\%) } \\
62 \text { (44.0\%) } \\
58(41.1 \%)\end{array}$ & $\begin{array}{l}|I .24 \pm 5.8| \\
|0.2| \pm 5.15 \\
\mid 2.40 \pm 4.29\end{array}$ & 0.09 \\
\hline
\end{tabular}

Note: *Average annual household income (thousand US Dollar).

affecting all aspects of our global and social health systems in unprecedented ways. ${ }^{9}$ During the COVID-19 epidemic, entire countries' medical resources and services of China were mainly pumped into anti-epidemic work, which has led to the neglect and delay of treatments of other diseases, especially cancer patients who are heavily dependent on medical resources and cannot be timely treated. ${ }^{10}$ Reasonable treatment strategies have become the focus of common concern of doctors and patients.
Although the epidemic situation in China has been effectively controlled after a painful period, crises of inadequate human resources for health care, financial and medical resources caused by the COVID-19 epidemic have already become a serious global issue; such situations of medical resource allocation and reorganization are being repeated throughout the rest of the world. ${ }^{11}$

The First Hospital of Xi'an Jiaotong University is a comprehensive specialized first-class tertiary hospital 
Table 2 Logistic Regression Analysis of Univariate Characteristics

\begin{tabular}{|l|l|l|l|}
\hline & \multirow{2}{*}{$P$ value } & \multicolumn{2}{|l|}{ HR 95\% CI } \\
\cline { 3 - 4 } & & Low & High \\
\hline Gender & 0.305 & -2.042 & 0.645 \\
Tumor location & 0.038 & -1.323 & -0.039 \\
Switch to oral chemotherapy & 0.042 & -3.278 & -0.064 \\
CAM & 0.03 & -2.737 & -0.141 \\
Advanced patients & 0.001 & 1.176 & 2.098 \\
Education & 0.455 & -0.429 & 0.193 \\
Knowing the purpose of chemotherapy & 0.013 & 0.184 & 1.542 \\
\hline
\end{tabular}

affiliated with the National Health Commission of China and a first-class nationally recognized regional medical cancer center covering the vast majority of cancer patients in northwestern China. The characteristics of patients enrolled in this study are fairly representative of patients in other geographic sites of China.

Patients with cancer often have poor immunity because of their disease and/or treatment and appear to be at increased risk of COVID-19 $9^{12}$. Moreover, their outcomes are worse than the general population without cancer. ${ }^{13}$ The COVID-19 epidemic has created a parallel epidemic of fear, anxiety and depression. Cancer patients may be affected by it due to a higher susceptibility to stress than the general population. ${ }^{14}$ Our research shows that anxiety is common in patients with malignant solid tumors, which is related to their belief that their disease cannot be treated in a timely manner. However, a subgroup analysis showed that the anxiety score of patients with lung cancer was significantly higher than that of other patients. This may be related to the inability of many patients with lung cancer to perform oral drug chemotherapy. ${ }^{15}$ Unlike other common solid tumor patients (such as breast cancer, colorectal cancer, and gastric cancer patients), who can convert to oral drugs, such as Capecitabine, for chemotherapy, many patients with lung cancer cannot match the corresponding genotype associated with oral chemotherapy. ${ }^{12}$ Moreover, lung cancer patients diagnosed with COVID-19 tend to have poorer outcomes and deteriorating conditions. ${ }^{16}$ A recent study also showed that hospital admissions and repeated clinic visits increase the risk of COVID-19 exposure for patients. ${ }^{1}$ Moreover, cancer patients' infection risks in tertiary hospital were more than twice as high as the cumulative incidence observed in the city of Wuhan over the same time period. ${ }^{17} \mathrm{~A}$ recent study suggested that $78 \%$ of confirmed patients were asymptomatic but represented "a formidable source" of contagion. ${ }^{18}$ These may all be the causes of patients' anxiety.

Our research shows that the majority of patients with solid tumors will choose at least one kind of CAM while undergoing oral drug chemotherapy. Generally, cancer patients prefer intravenous chemotherapy to oral chemotherapy because they do not consider oral chemotherapy to be as effective as intravenous chemotherapy. ${ }^{19}$ They do not think that oral chemotherapy alone can achieve the same effect as the previous treatment effect of intravenous chemotherapy. CAM is believed to improve their immune system and reduce the risks of COVID-19 infection. ${ }^{20}$ A related stratified analysis of our study showed that the delay in tumor treatment caused by COVID-19 is an independent factor of anxiety in patients with malignant solid tumors and has nothing to do with the patient's pain state or disease type. On the other hand, when patients with these tumors receive oral chemotherapy drugs, they are worried that their immune system will be suppressed and the risk of COVID-19 increased. This is also a dilemma.

For patients with advanced solid tumors, the anxiety score was significantly higher than that of other patients. Many of those patients who received palliative chemotherapy might have considered their cancers to be curative before the sudden interruption of chemotherapy. This clarification of the misunderstanding that their chemotherapy would not offer any possibility of cure may have dashed their hopes and optimism, causing fear and panic (Table 2). Physicians should clearly communicate the purpose of chemotherapy to advanced cancer patients before initiation since higher expectations will bring even greater disappointment. This phenomenon appears to be very universal and deserves particular attention. ${ }^{21}$

Our results suggested that telephone counseling offers certain advantages and is associated with better counseling outcomes in some patients with anxiety, which indicated that timely and comprehensive phone psychological support can reduce potential psychological damage caused by the interruption of chemotherapy during the epidemic (Figure 1). However, telephone follow-ups also show a certain bias, such as patients being affected by the media publicity of COVID-19 at that time or the background of their education.

Of our patients, $60.3 \%$ said they were considering adding CAM to their oral chemotherapy or using CAM alone, but only a small number (25.9\%) of them had informed or talked with their healthcare providers. The use of CAM mainly derived from an auto prescription 


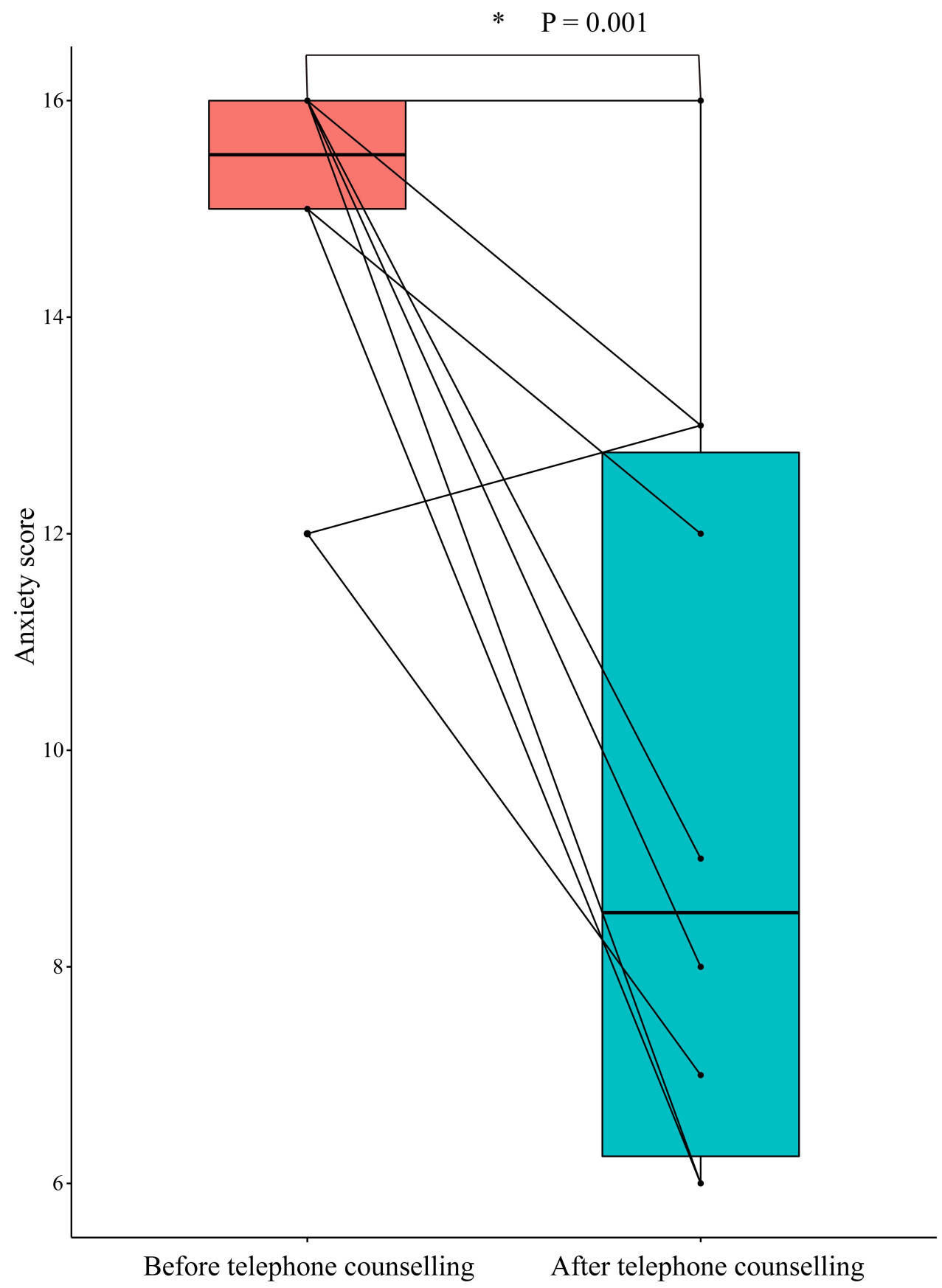

Figure I Counseling outcomes in 10 non-oral chemotherapy lung cancer patients with high anxiety score. $* P=0.00$ I.

(74.1\%), and most patients were not aware of the potential side effects. Some CAMs have undergone scientific evaluation and been found to be safe and effective; however, others have been found to be ineffective or possibly harmful, still requiring the guidance of doctors. ${ }^{22}$ When asked whether they had a good understanding of the CAM they chose, they responded that they were uncertain whether they would benefit from the CAM. However, they believed that the CAM they chose would at least give them some sort of psychological comfort. As Herzberg once said, "While scientific medicine focuses on cures of diseases, CAM is concerned with helping us to heal ourselves."

A switch from intravenous to provisional home-based oral chemotherapy is a feasible strategy. Telehealth or remote consults may be an option for patients checking in with healthcare providers. CAM may provide significant psychological support in such patients during this critical time. For 
advanced stage and incurable patients, physicians should improve patients' understanding before chemotherapy to lower overoptimistic expectations, and earlier psychological intervention and assistance should be applied in such patients. It is difficult to predict when the next pandemic will occur or how severe it will be. Wherever and whenever a pandemic starts, everyone around the world is at risk. Our study recognizes that, in the context of serious public health threats and public emergencies threatening the life of the nation, countries might provide mechanisms to facilitate equitable and prompt medical care to cancer patients who need it.

\section{Conclusion}

In this study, we focused on cancer patients whose chemotherapy treatment was interrupted due to the COVID-19 pandemic. In addition, alternative anti-cancer therapeutic strategies and patients' mental status were assessed by telephone interview. We found that oral chemotherapy or CAM could be alternative therapeutic methods during the pandemic. Further, anxiety was common in patients suffering advanced cancers, such as lung cancer, which indicated that more attention and mental support should be offered during this special period.

\section{Data Sharing Statement}

The full data of this study was available from the corresponding authors upon request.

\section{Ethics Approval and Informed Consent}

This study was conducted in accordance with the Declaration of Helsinki and approved by The Review Boards of Shaanxi Province Clinical Cancer Research Center affiliated to The First Affiliated Hospital of Xi'an Jiaotong University (No.SX-ZLLC-2020-09). Oral consents of participation from each patient were obtained before telephone interview starting.

\section{Author Contributions}

All authors made a significant contribution to the work reported, whether that is in the conception, study design, execution, acquisition of data, analysis and interpretation, or in all these areas; took part in drafting, revising or critically reviewing the article; gave final approval of the version to be published; have agreed on the journal to which the article has been submitted; and agree to be accountable for all aspects of the work.

\section{Funding}

This research received no specific grant from any funding agency in the public, commercial or not-for-profit sectors.

\section{Disclosure}

All authors declare that they have no conflicts of interest.

\section{References}

1. Zhou F, Yu T, Du R, et al. Clinical course and risk factors for mortality of adult inpatients with COVID-19 in Wuhan, China: a retrospective cohort study. The Lancet. 2020;395 (10229):1054-1062. doi:10.1016/S0140-6736(20)30566-3

2. Guo Y, Huang YM, Huang J, et al. [COVID-19 Pandemic: global epidemiological trends and China's subsequent preparedness and responses]. Zhonghua Liu Xing Bing Xue Za Zhi. 2020;41(5):643-648. Chinese.

3. Staehler M, Battle D, Pal SK, Bergerot CD. Counterbalancing COVID-19 with cancer surveillance and therapy: a survey of patients with renal cell carcinoma. Eur Urol Focus. 2020. doi:10.1016/j. euf.2020.09.002

4. Fujita K, Ito T, Saito Z, Kanai O. Impact of COVID-19 pandemic on lung cancer treatment scheduling. 2020;11(10):2983-2986. doi:10.11 11/1759-7714.13615

5. Wondie Y, Hinz A. Quality of life among Ethiopian cancer patients. Support Care Cancer. 2020;28(11):5469-5478. doi:10.1007/s00520020-05398-w

6. Romito F, Dellino M, Loseto G, et al. Psychological distress in outpatients with lymphoma during the COVID-19 pandemic. Front Oncol. 2020;10:1270. doi:10.3389/fonc.2020.01270

7. Agyapong VIO, Hrabok M. Closing the COVID-19 psychological treatment gap for cancer patients in alberta: protocol for the implementation and evaluation of text4hope-cancer care. 2020;9(8):e20240.

8. Dhont J, Di Tella M, Dubois L, et al. Conducting research in Radiation Oncology remotely during the COVID-19 pandemic: coping with isolation. Clin Transl Rad Oncol. 2020;24:53-59. doi:10.1016/j.ctro.2020.06.006

9. Leung K, Wu JT, Liu D, Leung GM. First-wave COVID-19 transmissibility and severity in China outside Hubei after control measures, and second-wave scenario planning: a modelling impact assessment. The Lancet. 2020;395(10233):1382-1393. doi:10.1016/ S0140-6736(20)30746-7

10. Wang C, Pan R, Wan X, et al. Immediate psychological responses and associated factors during the initial stage of the 2019 Coronavirus Disease (COVID-19) epidemic among the general population in China. Int J Environ Res Public Health. 2020;17(5).

11. Velavan TP, Meyer CG. The COVID-19 epidemic. Trop Med Int Health. 2020;25(3):278-280. doi:10.1111/tmi.13383

12. Chen DS, Mellman I. Oncology meets immunology: the cancer-immunity cycle. Immunity. 2013;39(1):1-10. doi:10.1016/j. immuni.2013.07.012

13. Al-Shamsi HO, Alhazzani W, Alhuraiji A, et al. A practical approach to the management of cancer patients during the novel Coronavirus Disease 2019 COVID-19) pandemic: an international collaborative group. Oncologist. 2020;25(6). doi:10.1634/theoncologist.2020-0213.

14. Lai J, Ma S, Wang Y, et al. Factors associated with mental health outcomes among health care workers exposed to Coronavirus Disease 2019. JAMA Netw Open. 2020;3(3):e203976. doi:10.1001/jamanetworkopen. 2020.3976

15. Mangal S, Gao W, Li T, Zhou QT. Pulmonary delivery of nanoparticle chemotherapy for the treatment of lung cancers: challenges and opportunities. Acta Pharmacol Sin. 2017;38(6):782-797. doi:10.10 38/aps.2017.34 
16. Calabrò L, Peters S, Soria J-C, et al. Challenges in lung cancer therapy during the COVID-19 pandemic. Lancet Respir Med. 2020;8(6):542-544. doi:10.1016/S2213-2600(20)30170-3

17. Guo ZD, Wang ZY, Zhang SF, et al. Aerosol and surface distribution of severe acute respiratory syndrome Coronavirus 2 in Hospital Wards, Wuhan, China, 2020. Emerg Infect Dis. 2020;26(7): 1583-1591. doi:10.3201/eid2607.200885

18. Al-Tawfiq JA. Asymptomatic coronavirus infection: MERS-CoV and SARS-CoV-2 (COVID-19). Travel Med Infect Dis. 2020;35:101608. doi:10.1016/j.tmaid.2020.101608

19. Sorensen SF, Carus A, Meldgaard P. Intravenous or oral administration of vinorelbine in adjuvant chemotherapy with cisplatin and vinorelbine for resected NSCLC. Lung Cancer. 2015;88(2):16 7-173. doi:10.1016/j.lungcan.2015.02.010
20. Shawahna R, Al-Atrash M. What do primary healthcare providers and complementary and alternative medicine practitioners in palestine need to know about exercise for cancer patients and survivors: a consensual study using the Delphi Technique. Evid Based Complement Alternat Med. 2019;2019:7695818. doi:10.1155/2019/7695818

21. Weeks JC, Catalano PJ, Cronin AM, et al. Patients' expectations about effects of chemotherapy for advanced cancer. $N$ Engl $J$ Med. 2012;367(17):1616-1625. doi:10.1056/NEJMoa1204410

22. Stub T, Quandt SA, Arcury TA, Sandberg JC, Kristoffersen AE. Attitudes and knowledge about direct and indirect risks among conventional and complementary health care providers in cancer care. BMC Complement Altern Med. 2018;18(1):44. doi:10.1186/s12906018-2106-z

\section{Publish your work in this journal}

Cancer Management and Research is an international, peer-reviewed open access journal focusing on cancer research and the optimal use of preventative and integrated treatment interventions to achieve improved outcomes, enhanced survival and quality of life for the cancer patient.
The manuscript management system is completely online and includes a very quick and fair peer-review system, which is all easy to use. Visit http://www.dovepress.com/testimonials.php to read real quotes from published authors. 